\title{
Self-Efficacy Levels Regarding Interprofessional Learning Skills Among Undergraduate Healthcare Students in Malaysia
}

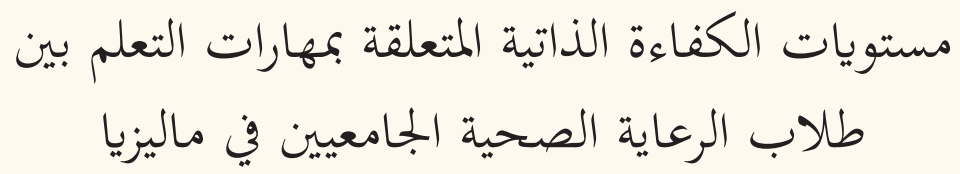

محمد سعيد نورمال، نورال قمرية هيرو ديونو، محمد كامل تشي حسن

ABSTRACT: Objectives: Self-efficacy is an important factor in determining the ability of students to execute tasks or skills needed in the implementation of interprofessional learning (IPL). This study aimed to identify levels of self-efficacy with regards to IPL skills among undergraduate healthcare students and to investigate differences according to gender, programme of study and year of study. Methods: This descriptive cross-sectional study was conducted between January and March 2018 at the International Islamic University Malaysia, Kuantan, Malaysia. The Self-Efficacy for Interprofessional Experiential Learning scale was used to evaluate the self-efficacy of 336 students from five faculties including nursing, medicine, dentistry, pharmacy and allied health sciences. Results: Significant differences in self-efficacy scores for the interprofessional interaction subscale were identified according to programme of study, with pharmacy students scoring significantly lower than allied health students (mean score: $54.1 \pm 10.4$ versus $57.4 \pm 10.1 ; P=0.014$ ). In addition, there was a significant difference in self-efficacy scores for the interprofessional interaction subscale according to year of study, with first-year students scoring significantly lower compared to fifth-year students (mean score: $52.8 \pm 10.4$ versus $59.9 \pm$ $11.9 ; P=0.018$ ). No statistically significant differences in self-efficacy scores were identified with regards to gender or for the interprofessional team evaluation and feedback subscale. Conclusion: These findings may contribute to the effective implementation of IPL education in healthcare faculties. Acknowledging the influence of self-efficacy on the execution of IPL skills is crucial to ensure healthcare students are able to adequately prepare for future interprofessional collaboration in real clinical settings.

Keywords: Self Efficacy; Intersectoral Collaboration; Interdisciplinary Research; Professional Competence; Learning; Undergraduate Medical Education; Malaysia.

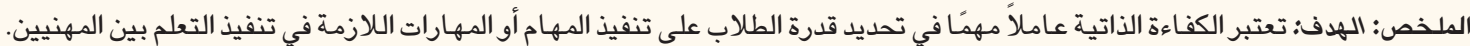

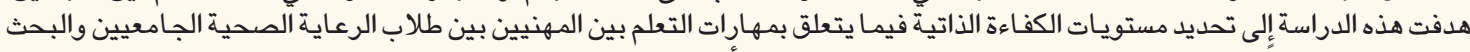

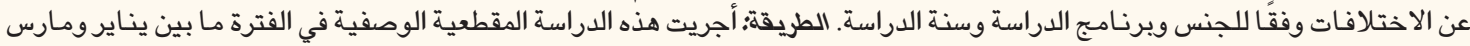

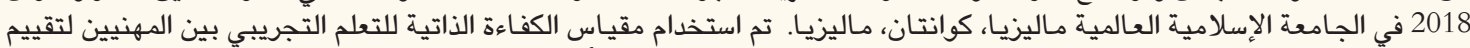

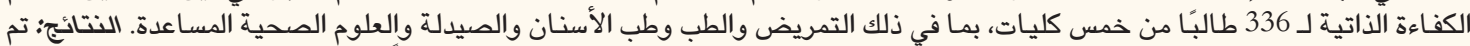

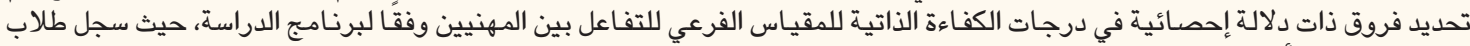

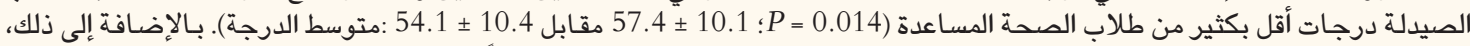

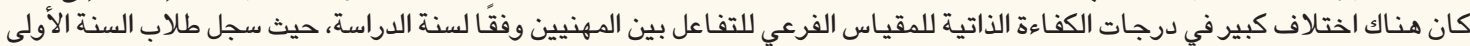

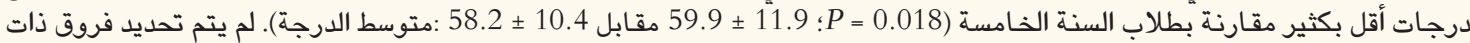

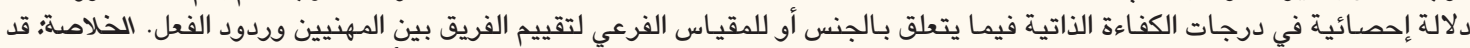

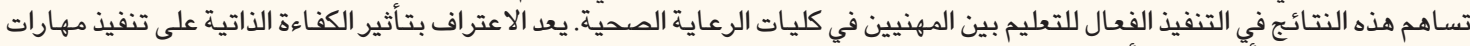

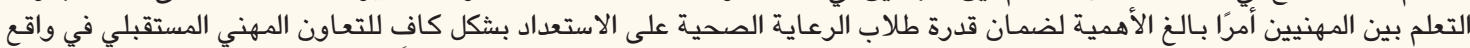
البيئة السريرية.

الكلمات المفتاحية: الكفاءة الذاتية؛ التعاون بين القطاعات؛ بحث متعدد التخصصات؛ الكفاءة الههنية؛ التعلم؛ التعليم الطبي في المرحلة

\section{ADVANCES IN KNOWLEDGE}

The current study found that healthcare students studying at a university in Malaysia demonstrated moderately-high levels of selfefficacy with regards to interprofessional learning (IPL) skills.

However, there was a significant difference in self-efficacy scores according to programme of study, with pharmacy students scoring significantly lower compared to those enrolled in allied health sciences. 


\section{Application to Patient Care}

Overall, IPL is an indirect yet important aspect of patient care, given that modern healthcare treatment and services has become a collaborative endeavour involving healthcare professionals from multiple specialties. As such, ensuring that students attain a high level of self-efficacy in IPL skills will ensure no redundancy of care or information in their future clinical practice.

$\mathrm{I}$ N MODERN HEALTHCARE, THE CAPACITY TO DEAL with complex medical problems is enhanced immeasurably by the sharing of values, knowledge and skills across different specialties. ${ }^{1}$ To this end, the World Health Organization utilises the term interprofessional learning (IPL) to describe the skills shown when individuals from different healthcare professions work together in order to provide high-quality care. ${ }^{2}$ According to the Centre for the Advancement of Interprofessional Education, IPL is defined as active learning occasions when "two or more professions learn with, from and about each other to improve collaboration and quality of care." The goal of IPL is to enhance health outcomes via effective interprofessional collaboration, thereby improving the quality of care as well as patient safety. ${ }^{4}$

Self-efficacy refers to an individual's perceptions of their own competency with regards to the performance of a skill or task. ${ }^{5}$ The confidence level of an individual regarding their ability to perform can be an important factor affecting the outcomes of the action(s) taken and can influence and modify human behaviour. ${ }^{6}$ Multiple studies have shown that self-efficacy appears to be a substantial contributor to student learning outcomes particularly in undergraduate healthcare IPL education..$^{7-11}$ All students in health professions are expected to demonstrate high levels of personal efficacy and competency in the skills required for the establishment of an effective learning environment and a constructive learning experience. ${ }^{12}$ Moreover, becoming more confident in certain skills can also empower students to more effectively handle complex and stressful situations, an important quality when treating ailments and managing patients. ${ }^{13}$

Despite the importance of IPL in modern healthcare practice, no structured IPL education has yet been incorporated officially within the undergraduate healthcare curricula in Malaysia. Thus, this study was conducted to identify levels of self-efficacy regarding IPL skills among a cohort of undergraduate students enrolled in various healthcare-related programmes at a university in Malaysia and to investigate potential differences in self-efficacy according to gender, programme of study and year of study.

\section{Methods}

This descriptive cross-sectional study took place between January and March 2018 at the International
Islamic University Malaysia (IIUM), Kuantan, Malaysia. A convenience sample of undergraduate students aged between 19-25 years was recruited from five healthcare faculties including the medicine, dentistry, pharmacy, nursing and allied health sciences faculties. All students had clinical postings involving personnel outside of their chosen profession. The required sample size was calculated to be 299 out of a total of 1,343 potential participants, assuming that the level of self-efficacy would be $50 \%$ and with a 95\% confidence interval and a margin of error of 5\%. Accordingly, a total of 336 undergraduate healthcare students were recruited.

Levels of self-efficacy were assessed using an English questionnaire which incorporated the 16item Self-Efficacy for Interprofessional Experiential Learning (SEIEL) scale. ${ }^{14}$ This tool was chosen as it is specifically designed to measure students' perceptions of their ability to execute skills and tasks as they relate to interprofessional practice. The SEIEL scale consists of two subscales covering interprofessional interaction and interprofessional team evaluation and feedback. ${ }^{14}$ The former focuses on assessing students' self-efficacy in skills that enable them to work and communicate effectively with other students from multidisciplinary healthcare programmes, whereas the latter assesses self-efficacy regarding the use of higher-level skills associated with evaluating, understanding and providing feedback on the quality of interprofessional interactions. Each subscale consists of eight items scored from 1 to 10 , resulting in a total score ranging from $8-80$. $^{14}$

In order to test the validity and reliability of the questionnaire, a pilot study was conducted among 30 second-, third- and fourth-year nursing students at IIUM who were subsequently excluded from the main sample. The findings revealed that the tool had excellent internal consistency (Cronbach's alpha: 0.96-0.97). As such, the questionnaire was distributed to the recruited students via class representatives for each of the programmes.

The Statistical Package for the Social Sciences (SPSS), Version 20 (IBM Corp., Armonk, New York, USA), was used to analyse the data. Descriptive statistics were used to present findings regarding the students' level of self-efficacy for IPL skills with higher mean SEIEL scores indicating greater levels of self-efficacy in terms of IPL skills. An independent sample t-test was conducted to compare mean 
SEIEL scores according to gender, while a one-way analysis of variance was computed to compare scores according to programme and year of study. Post-hoc comparisons were performed using Tukey's multiple comparison test. Results were considered statistically significant at $P<0.050$.

Ethical approval for this study was obtained from the Kulliyyah of Nursing Postgraduate Research Committee (\#IIUM/313/DDAA/20/4/10) as well as the International Islamic University Malaysia Research Ethics Committee (\#IIUM/504/14/11/2/IREC 2018026). All students gave informed consent prior to completing the questionnaire.

\section{Results}

The demographic characteristics of the participants are presented in Table 1. Overall, the undergraduate healthcare students demonstrated moderately high levels of self-efficacy with regards to both the interprofessional interaction (mean score: $57.4 \pm 10.1$ ) and interprofessional team evaluation and feedback (mean score: $55.7 \pm 9.7$ ) subscales of the SEIEL tool.

No significant differences in self-efficacy were observed according to gender, with male and female students demonstrating comparable overall mean SEIEL scores (mean overall score: $114.6 \pm 18.5$ versus 112.4 $\pm 19.3 ; P=0.322$ ). Similar findings were noted among male and female participants for the individual subscales of interprofessional interaction (mean

Table 1: Demographic characteristics of healthcare students at the International Islamic University Malaysia, Kuantan, Malaysia $(\mathrm{N}=336)$

$\begin{array}{lc}\text { Characteristic } & \mathbf{n}(\%) \\ \text { Gender } & \\ \text { Male } & 99(29.5) \\ \text { Female } & 237(70.5) \\ \text { Year of study } & \\ 1 & 13(3.9) \\ 2 & 13(3.9) \\ 3 & 128(38.1) \\ 4 & 132(39.3) \\ 5 & 50(14.9) \\ \text { Programme of study } & \\ \text { Nursing } & 54(16.1) \\ \text { Medicine } & 107(31.8) \\ \text { Pharmacy } & 53(15.8) \\ \text { Dentistry } & 38(11.3) \\ \text { Allied health sciences } & 84(25) \\ \end{array}$

score: $58.1 \pm 9.8$ versus $57.1 \pm 10.2 ; P=0.383)$ and interprofessional team evaluation and feedback (mean score: $56.5 \pm 9.3$ versus $55.3 \pm 9.8 ; P=0.295$ ) [Table 2]

Significant differences in self-efficacy were observed with regards to programme of study, with pharmacy students scoring significantly lower than allied health sciences for the interprofessional interaction subscale (mean score: $54.1 \pm 10.4$ versus 57.4 $\pm 10.1 ; P=0.014$ ) [Table 3]. Moreover, there was a significant difference according to year of study, with first-year students scoring significantly lower compared to fifth-year students for the interprofessional interaction subscale (mean score: $52.8 \pm 10.4$ versus $59.9 \pm 11.9 ; P=0.018$ ) [Table 4] . However, neither programme nor year of study had a significant effect on scores for the interprofessional team evaluation and feedback subscale.

\section{Discussion}

Preparing healthcare students for future collaborative practice in the workplace is essential, particularly as current treatment and management of medical issues usually involves multiple disciplines and professions. As such, all healthcare students need to understand that working together across discipline boundaries is vital. ${ }^{15}$ Previous research suggests that high selfefficacy has positive effects on students' self-regulation strategies and academic performance in educational settings. ${ }^{16,17}$ Simulation-based learning is a potential teaching method which exposes students to clinical scenarios in which IPL skills can be integrated..$^{18}$ In addition, students have been shown to demonstrate positive attitudes towards IPL based on feedback from subsequent debriefing sessions. ${ }^{19}$ This study found that undergraduate healthcare students at a university in Malaysia demonstrated a moderately high level of selfefficacy when executing IPL skills. With time, the idea of implementing IPL into the healthcare curriculum is

Table 2: Level of self-efficacy in interprofessional learning skills according to gender among healthcare students at the International Islamic University Malaysia, Kuantan, Malaysia $(\mathrm{N}=336)$

\begin{tabular}{lccc|} 
Subscale & \multicolumn{2}{c}{ Mean score ${ }^{*} \pm$ SD } & P value \\
& $\begin{array}{c}\text { Male } \\
(\mathbf{n}=\mathbf{9 9})\end{array}$ & $\begin{array}{c}\text { Female } \\
(\mathbf{n}=237)\end{array}$ & \\
& $58.1 \pm 9.8$ & $57.1 \pm 10.2$ & 0.383 \\
$\begin{array}{l}\text { Interprofessional } \\
\text { interaction }\end{array}$ & & & \\
$\begin{array}{l}\text { Interprofessional } \\
\text { team evaluation } \\
\text { and feedback }\end{array}$ & $56.5 \pm 9.3$ & $55.3 \pm 9.8$ & 0.295 \\
$\begin{array}{l}\text { Overall } \\
\text { Overall }\end{array}$ & $114.6 \pm 18.5$ & $112.4 \pm 19.3$ & 0.322
\end{tabular}

$S D=$ standard deviation. *Assessed using the Self-Efficacy for Interprofessional Experiential Learning scale. ${ }^{14}$ 
Table 3: Level of self-efficacy in interprofessional learning skills according to programme of study among healthcare students at the International Islamic University Malaysia, Kuantan, Malaysia $(\mathrm{N}=336)$

\begin{tabular}{|c|c|c|c|c|c|c|}
\hline \multirow[t]{2}{*}{ Subscale } & \multicolumn{5}{|c|}{ Mean score $^{*} \pm$ SD } & \multirow[t]{2}{*}{$P$ value } \\
\hline & $\begin{array}{l}\text { Nursing } \\
(\mathrm{n}=54)\end{array}$ & $\begin{array}{l}\text { Medicine } \\
(\mathrm{n}=107)\end{array}$ & $\begin{array}{l}\text { Pharmacy } \\
(\mathrm{n}=53)\end{array}$ & $\begin{array}{l}\text { Dentistry } \\
(\mathbf{n}=38)\end{array}$ & $\begin{array}{l}\text { Allied health } \\
\text { sciences } \\
(\mathrm{n}=84)\end{array}$ & \\
\hline $\begin{array}{l}\text { Interprofessional } \\
\text { interaction }\end{array}$ & $55.1 \pm 10.0$ & $58.5 \pm 9.3$ & $54.1 \pm 10.4$ & $58.9 \pm 9.1$ & $57.4 \pm 10.1$ & $0.014^{\dagger}$ \\
\hline $\begin{array}{l}\text { Interprofessional team } \\
\text { evaluation and feedback }\end{array}$ & $54.6 \pm 9.0$ & $56.3 \pm 8.3$ & $53.6 \pm 9.5$ & $56.8 \pm 12.0$ & $56.3 \pm 9.3$ & 0.351 \\
\hline Overall & $109.7 \pm 18.5$ & $114.9 \pm 17.1$ & $107.7 \pm 19.2$ & $115.2 \pm 18.9$ & $113.0 \pm 19.1$ & 0.075 \\
\hline
\end{tabular}

$S D=$ standard deviation. "Assessed using the Self-Efficacy for Interprofessional Experiential Learning scale. ${ }^{14}{ }^{+}$Statistically significant at $P<0.050$.

Table 4: Level of self-efficacy in interprofessional learning skills according to year of study among healthcare students at the International Islamic University Malaysia, Kuantan, Malaysia $(\mathrm{N}=336)$

\begin{tabular}{|c|c|c|c|c|c|c|}
\hline \multirow[t]{2}{*}{ Subscale } & \multicolumn{5}{|c|}{ Mean score \pm SD } & \multirow[t]{2}{*}{$P$ value } \\
\hline & Year $1(n=13)$ & Year $2(n=13)$ & Year $3(n=128)$ & Year $4(n=132)$ & Year $5(n=50)$ & \\
\hline $\begin{array}{l}\text { Interprofessional } \\
\text { interaction }\end{array}$ & $52.8 \pm 10.4$ & $53.2 \pm 9.6$ & $56.1 \pm 9.1$ & $58.5 \pm 10.0$ & $59.9 \pm 11.9$ & $0.018^{\dagger}$ \\
\hline $\begin{array}{l}\text { Interprofessional team } \\
\text { evaluation and feedback }\end{array}$ & $51.2 \pm 8.8$ & $54.2 \pm 9.7$ & $54.9 \pm 9.1$ & $56.5 \pm 9.5$ & $57.1 \pm 11.4$ & 0.204 \\
\hline Overall & $104.0 \pm 18.9$ & $107.9 \pm 18.8$ & $110.9 \pm 17.3$ & $115.0 \pm 18.9$ & $116.9 \pm 22.9$ & 0.059 \\
\hline
\end{tabular}

$S D=$ standard deviation. "Assessed using the Self-Efficacy for Interprofessional Experiential Learning scale. ${ }^{14}{ }^{+}$Statistically significant at $P<0.050$.

gradually being adopted around the globe including in Asia. ${ }^{20}$

In the current study, no significant differences in self-efficacy scores were found according to gender. This finding is in line with those observed by Nørgaard et al. during a quasi-experimental study. ${ }^{21}$ Similarly, Vuong et al. also reported no significant differences in levels of self-efficacy between students of either gender in terms of academic success. ${ }^{22}$ Interestingly, other studies have published contradictory findings. For instance, a meta-analysis indicated that levels of self-efficacy in language or the arts are usually higher in females, whereas males show greater self-efficacy in mathematics or computer science. ${ }^{23}$ This difference might be more pronounced for domain-specific selfefficacy as existing research indicates that the strength and direction of gender differences varies with subject and area of interest. ${ }^{16}$ Other factors likely also play a role and should be investigated, including the individual's interest, willingness to learn and preferred learning style, in order to determine whether these aspects directly or indirectly influence levels of self-efficacy between genders. Showing interest and willingness to learn is a major factor contributing to self-efficacy. ${ }^{24}$

Williams et al. reported that neither subscale of the SEIEL instrument was able to assess a significant difference in the level of self-efficacy between healthcare disciplines. ${ }^{25}$ In contrast, the current study highlighted an interesting finding in which significant differences in self-efficacy scores for the interprofessional interaction subscale arose according to programme of study, particularly between students of two different programmes (i.e. pharmacy and allied health sciences). These mean scores reflect a small difference which does not necessarily contradict the previous study which found no significant difference with regard to healthcare disciplines. ${ }^{25}$ However, there is no explanation as to why this happens and larger longitudinal studies are required for further clarification. The authors of the current study speculate that different healthcare curricula may offer unique learning opportunities throughout the course of study which will result in variations in IPL self-efficacy.

In addition, other factors may have influenced the outcomes of the present study such as the varying involvement of the students with patient care and differences in terms of degree of interaction with other professions during clinical practice. Moreover, it is important to note that students in allied health sciences programmes are frequently exposed to other disciplines namely audiology, optometry, physiotherapy, radiography and dietetics; in addition, these students are often more heavily involved in patient care and actively participate in multidisciplinary interactions and research during their course of study. In contrast, pharmacy students tend to focus primarily 
on reviewing and supplying prescribed drugs and may therefore be less involved in actual patient care or have less direct contact with other healthcare professionals.

Hall stated that each healthcare profession has a different culture, with unique values, beliefs, attitudes, customs and behaviours. ${ }^{26}$ Educational experiences and socialisation processes that take place during training also reinforce the common values and problemsolving approaches of each profession. This increased specialisation may lead to learners becoming further immersed in their own professional group. Indirectly, these factors might contribute to differences in the level of self-efficacy in IPL skills observed in students in the current study.

Year of study was not found to significantly affect levels of self-efficacy for subscale interprofessional team evaluation and feedback of the SEIEL instrument in the present study. Similar results were reported in Williams et al's study, which showed a non-significant difference in IPL self-efficacy with regards to study year. ${ }^{25}$ In contrast, other studies have noted that students in their senior years appear to have a higher level of self-efficacy compared to junior students. ${ }^{24,27}$ Increasing maturity on the part of the students could potentially lead to an increase in their levels of selfefficacy, both as a natural result of getting older and as they progress further in their studies.

Both the knowledge as well as the clinical experience attained during senior years might be a contributory factor to increased self-efficacy. ${ }^{24}$ Other external factors might also exist which have not been highlighted in this research. Undergraduate healthcare students, irrespective of their year of study, might have been exposed early to the importance of IPL via indirect discussion as well as during specific courses. In fact, many educators nowadays actively implement teaching and learning strategies that may offer students the opportunity to attain the skills necessary to function effectively as a member of an interprofessional team in real practical settings. ${ }^{28}$ Simulation exercises, for example, are just one of many effective learning strategies to enhance self-confidence and reduce anxiety among healthcare students, particularly when it comes to caring for patients. ${ }^{8,12}$

A limitation of this study was the inability to generalise findings as the participants consisted solely of students from a single university. As such, larger longitudinal studies involving greater sample sizes are necessary to further explore this phenomenon. Other factors such as support, the involvement of peers and the use of simulation in both the academic and clinical performance of healthcare students should also be considered particularly when seeking to determine an individual student's level of self-efficacy for the entire duration of study. Further research is also needed to clarify how self-efficacy relates to clinical learning as this may become a foundation from which to initiate positive changes to healthcare education in the future. $^{29}$

\section{Conclusion}

This study found that IIUM undergraduate students from five different healthcare-related programmes exhibited moderately-high levels of self-efficacy with regards to their IPL skills. Self-efficacy in the execution of IPL skills is crucial to ensure students can adequately prepare themselves for future interdisciplinary collaboration in real-life clinical settings. Ideally, these findings may contribute to the more effective and standardised implementation of IPL skills in healthcare curricula in the future.

\section{CONFLICT OF INTEREST}

The authors declare no conflicts of interest.

\section{FUNDING}

No funding was received for this study.

\section{References}

1. Olenick M, Allen LR. Faculty intent to engage in interprofessional education. J Multidiscip Healthc 2013; 6:149-61. https://doi.org/10.2147/JMDH.S38499.

2. World Health Organization. Framework for action on interprofessional education and collaborative practice. From: www.who.int/hrh/resources/framework_action/en/ Accessed: Feb 2020.

3. Dahlberg J, Falk AL, Kjellgren K, Dahlgren MA. Creating a common curriculum for interprofessional learning: Strategic development of undergraduate programs in medicine and health. From: www.iced2014.se/proceedings/1514 Abrandt\%20Dahlgren.pdf Accessed: Feb 2020.

4. Leotsakos A, Ardolino A, Cheung R, Zheng H, Barraclough B, Walton M. Educating future leaders in patient safety. J Multidiscip Healthc 2014; 7:381-8. https://doi.org/10.2147/ JMDH.S53792.

5. Hughes A, Galbraith D, White D. Perceived competence: A common core for self-efficacy and self-concept? J Pers Assess 2011; 93:278-89. https://doi.org/10.1080/00223891.2011.559390.

6. Bandura A. Self-efficacy: Toward a unifying theory of behavioral change. Psychol Rev 1977; 84:191-215. https://doi. org/10.1037//0033-295x.84.2.191.

7. Bartimote-Aufflick K, Bridgeman A, Walker R, Sharma M, Smith L. The study, evaluation, and improvement of university student self-efficacy. Stud High Educ 2016; 41:1918-42. https:// doi.org/10.1080/03075079.2014.999319.

8. Labrague LJ, McEnroe-Petitte DM, Bowling AM, Nwafor CE, Tsaras K. High-fidelity simulation and nursing students' anxiety and self-confidence: A systematic review. Nurs Forum 2019; 54:358-68. https://doi.org/10.1111/nuf.12337. 
9. Baaij A, Özok AR, Væth M, Musaeus P, Kirkevang LL. Selfefficacy of undergraduate dental students in endodontics within Aarhus and Amsterdam. Int Endod J 2019; 53:276 -84. https://doi.org/10.1111/iej.13218.

10. Inuwa IM. Interprofessional education (IPE) activity amongst health sciences students at Sultan Qaboos University: The time is now! Sultan Qaboos Univ Med J 2012; 12:435-41. https://doi. org/10.12816/0003168.

11. Brock D, Abu-Rish E, Chiu CR, Hammer D, Wilson S, Vorvick L, et al. Interprofessional education in team communication: Working together to improve patient safety. Postgrad Med J 2013; 89:642-51. https://doi.org/10.1136/postgradmedj-2012000952rep.

12. Khan NS, Shahnaz SI, Gomathi KG. Currently available tools and teaching strategies for the interprofessional education of students in health professions: Literature review. Sultan Qaboos Univ Med J 2016; 16:e277-85. https://doi.org/10.18295/squ mj.2016.16.03.003

13. Riesen E, Morley M, Clendinneng D, Ogilvie S, Murray MA. Improving interprofessional competence in undergraduate students using a novel blended learning approach. J Interprof Care 2012; 26:312-18. https://doi.org/10.3109/13561820.2012.660286.

14. Mann K, McFetridge-Durdle J, Breau L, Clovis J, MartinMisener R, Matheson $\mathrm{T}$, et al. Development of a scale to measure health professions students' self-efficacy beliefs in interprofessional learning. J Interprof Care 2012; 26:92-9. https://doi.org/10.3109/13561820.2011.640759.

15. Mayo AT, MS, Woolley AW. Teamwork in health care: Maximizing collective intelligence via inclusive collaboration and open communication. AMA J Ethics 2016; 18:933-40. https://doi.org/10.1001/journalofethics.2016.18.9.stas2-1609.

16. Schnell K, Ringeisen T, Raufelder D, Rohrmann S. The impact of adolescents' self-efficacy and self-regulated goal attainment processes on school performance: Do gender and test anxiety matter? Learn Individ Differ 2015; 38:90-8. https://doi.org/10.1 016/j.lindif.2014.12.008.

17. Williams B, Beovich B, Ross L, Wright C, Ilic D. Self-efficacy perceptions of interprofessional education and practice in undergraduate healthcare students. J Interprof Care 2017; 31:335-41. https://doi.org/10.1080/13561820.2017.1286637.

18. Alinier G, Harwood C, Harwood P, Montague S, Huish E, Ruparelia K, et al. Immersive clinical simulation in undergraduate health care interprofessional education: Knowledge and perceptions. Clin Simul Nurs 2014; 10:e205-16. https://doi. org/10.1016/j.ecns.2013.12.006
19. Honan L, Fahs DB, Talwalkar JS, Kayingo G. Interprofessional learning: Perceptions of first year health students. J Nurs Educ Pract 2015; 5:39-49. https://doi.org/10.5430/jnep.v5n6p39.

20. Lestari E, Stalmeijer RE, Widyandana D, Scherpbier A. Understanding students' readiness for interprofessional learning in an Asian context: A mixed-methods study. BMC Med Educ 2016; 16:179. https://doi.org/10.1186/s12909-016-0704-3.

21. Nørgaard B, Draborg E, Vestergaard E, Odgaard E, Jensen DC, Sørensen J. Interprofessional clinical training improves selfefficacy of health care students. Med Teach 2013; 35:e1235-42. https://doi.org/10.3109/0142159X.2012.746452.

22. Vuong M, Brown-Welty S, Tracz S. The effects of self-efficacy on academic success of first-generation college sophomore students. J Coll Stud Dev 2010; 51:50-64. https://doi.org/1 0.1353/csd.0.0109.

23. Huang C. Gender differences in academic self-efficacy: A meta-analysis. Eur J Psychol Educ 2013; 28:1-35. https://doi. org/10.1007/s10212-011-0097-y.

24. Jones SH. Nursing students' perceptions of working with staff nurses. MSN Thesis, 2010, Montana State University, Bozeman, Montana, USA.

25. Williams B, Beovich B, Ross L, Wright C, Ilic D. Self-efficacy perceptions of interprofessional education and practice in undergraduate healthcare students. J Interprof Care 2017; 31:335-41. https://doi.org/10.1080/13561820.2017.1286637.

26. Hall P. Interprofessional teamwork: Professional cultures as barriers. J Interprof Care 2005; 19:188-96. https://doi.org/10. 1080/13561820500081745.

27. Mueller SA, Naragon RM, Smith RR. The relationship between nursing students' perceptions of staff nurses' attitudes towards them and self-efficacy in sophomore- and senior-level nursing students. Honours Research Project, 2016, University of Akron, Akron, Ohio, USA.

28. Rossler KL, Buelow JR, Thompson AW, Knofczynski G. Effective learning of interprofessional teamwork. Nurse Educ 2017; 42:67-71. https://doi.org/10.1097/NNE.0000000000000313.

29. Townsend L, Scanlan JM. Self-efficacy related to student nurses in the clinical setting: A concept analysis. Int J Nurs Educ Scholarsh 2011; 8: 1-15. https://doi.org/10.2202/1548923X.2223. 